\title{
The perfect match
}

Interleukin-2 (IL-2) is a cytokine required in both mounting and dampening immune responses. IL-2 is involved in the expansion, survival and activation of effector $T$ cells and has been used in combination with adoptive transfer of $\mathrm{T}$ cells in cancer to overcome some of the limitations of this approach, such as the failure of transferred $T$ cells to persist and remain functional. However, IL-2 also activates regulatory $\mathrm{T}$ cells ( $\mathrm{T}_{\text {reg }}$ cells), which inhibit antitumour immunity, and is associated with capillary leak syndrome, a dose-limiting toxic effect.

On the basis of previous work that had determined the structure of the high-affinity IL-2 receptor (IL-2R)-IL-2 complex, the team led by Christopher Garcia was interested in refining the specificity of this receptor-ligand interaction in order to expand effector $\mathrm{T}$ cells while avoiding the expansion of $\mathrm{T}_{\text {reg }}$ cells. To that end, they generated a mutant IL-2 cytokine and a mutant IL-2R that would bind specifically to one another but not to their wild-type counterparts. To generate the mutant receptor, the authors chose IL-2R $\beta$ because the $\beta$-chain is required for both signal transduction and IL-2 binding.

First, the authors identified those mutations in IL-2R $\beta$ that prevented binding to endogenous, wild-type IL-2 and selected a double mutant (orthoIL-2R $\beta$ ) that lacked detectable binding to IL-2. Then, they randomly mutated IL-2 and selected two mutants (orthoIL-2s) that selectively bound orthoIL-2R $\beta$. OrthoIL-2 $3 \mathrm{~A} 10$ did not bind to wild-type IL-2R and bound orthoIL-2R $\beta$ with reduced affinity than that with which IL- 2 binds IL-2R $\beta$, whereas orthoIL-2 $1 \mathrm{G} 12$ showed high affinity for orthoIL-2R $\beta$ but also bound wild-type IL-2R $\beta$ with low affinity.

In vitro, treatment with orthoIL-2 $3 \mathrm{~A} 10$ specifically expanded primary mouse $\mathrm{CD}^{+} \mathrm{T}$ cells that had been engineered to express orthoIL-2R $\beta$ but not wild-type $\mathrm{T}$ cells. In vivo, twice-daily administration of high doses of orthoIL-2 3A10 resulted in substantial expansion of orthoIL-2R $\beta$ $\mathrm{CD} 8^{+} \mathrm{T}$ cells with no effect on wildtype T cells. Expanded orthoIL-2R $\beta$ T cells also produced significantly more interferon- $\gamma$ than wild-type T cells treated with IL-2.

Finally, the authors investigated the potential clinical applications of the orthogonal IL-2-IL-2R complexes in the B16-F10 mouse model of melanoma. Adoptive transfer of $\mathrm{T}$ cells engineered to recognize the B16-F10 melanoma cells and to express orthoIL-2R $\beta$, followed by treatment with orthoIL-2 3A10 (or orthoIL-2 1 G12 at a dose that had minimal activity on wild-type IL-2R cells) produced a significant tumour growth delay and survival

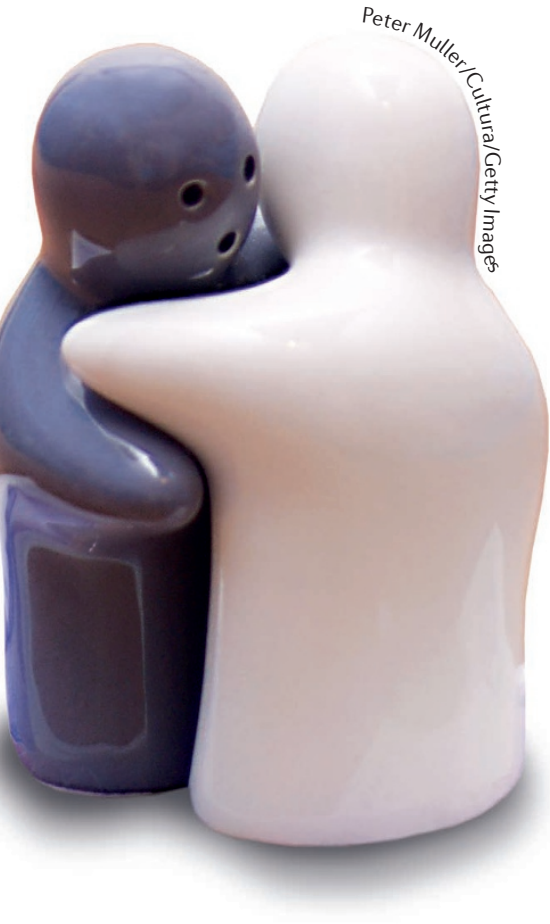

advantage similar to that observed in mice treated with T cells and IL-2. Importantly, orthoIL-2 3A10 administration resulted in less toxicity than orthoIL-2 $1 \mathrm{G} 12$ - possibly owing to the low-affinity activation of wildtype IL-2R $\beta$ - or administration of IL-2.

"The fact that we can

selectively activate signalling pathways on cells expressing the orthogonal receptor in vivo without activating signalling on cells native to the animal opens up the possibility that this approach could be used in adoptive cell therapy (ACT) in humans to enhance engineered or chimeric antigen receptor (CAR) T cell persistence, mitigate exhaustion and other current problems with ACT," says Garcia.

These results also open the door for generating other pairs of cytokine-cytokine receptors to harness the desirable signalling pathways while avoiding undesirable effects. "One can deliver any signal using this kind of technology for other orthogonal ligand-receptors", concludes Garcia.

M. Teresa Villanueva

pathways

while avoiding undesirable effects
ORIGINAL ARTICLE Sockolosky, J. T. et al. Selective targeting of engineered T cells using orthogonal IL-2 cytokine-receptor complexes. Science 359, 1037-1042 (2018) 